\title{
Multi-Battle Contests: An Experimental Study ${ }^{*}$
}

\author{
Shakun D. Mago a and Roman M. Sheremeta ${ }^{\mathrm{b}}$ \\ ${ }^{a}$ Department of Economics, Robins School of Business, University of Richmond, \\ 28 Westhampton Way, Richmond, VA 23173, USA \\ ${ }^{\mathrm{b}}$ Argyros School of Business and Economics, Chapman University, \\ One University Drive, Orange, CA 92866, USA
}

March 21, 2012

\begin{abstract}
This study examines behavior of subjects in simultaneous and sequential multi-battle contests. In simultaneous contests, subjects make positive bids in each battle $80 \%$ of the time and bids fall within the predicted boundaries. However, $35 \%$ of the time subjects make positive bids in only two, instead of all three, battles and they significantly overuse moderately high bids. In sequential contests, theory predicts sizable bids in the first battle and no bids in the subsequent battles. Contrary to this prediction, subjects significantly underbid in the first battle and overbid in subsequent battles. Consequently, instead of always ending in the second battle, contest proceeds to the third battle $38 \%$ of the time. Finally, in both simultaneous and sequential settings, subjects make higher aggregate bids than predicted resulting in negative expected payoffs.
\end{abstract}

JEL Classifications: C72, C91, D72

Keywords: multi-battle contest, experiments, risk aversion, overdissipation

Corresponding author: Roman M. Sheremeta; E-mail: sheremet@chapman.edu

* For helpful comments we thank Tim Cason, Rachel Croson, Subhasish M. Chowdhury, Dan Kovenock, Brian Roberson, Nat Wilcox, seminar participants at Chapman University, and participants at the North American Economic Science Association Conference in Tucson, 2011 International Foundation for Research in Experimental Economics Conference, International Economic Science Association Conference in Chicago, and the Southern Economic Association Conference in Washington D.C. Any errors are our responsibility. 


\section{Introduction}

In multi-battle contests, players expend resources in order to win a series of individual battles and the player who wins a certain pre-determined number of battles receives the prize for victory in the overall contest. These contests can be characterized along a number of different dimensions such as asymmetry between contestants, asymmetry in objectives, number of battles, interdependency between battles, and the sequence of play. Over the years, significant theoretical advancements have been made in examining how these factors impact individual behavior in multi-battle contests, resulting in a number of interesting predictions in the fields of patent races (Dasgupta, 1986; Konrad and Kovenock, 2009), R\&D competitions (Harris and Vickers, 1985, 1987), multi-unit auctions (Szentes and Rosenthal, 2003), sports championship series (Szymanski, 2003), network security (Hausken, 2008; Levitin and Hausken, 2010), elections (Snyder, 1989; Klumpp and Polborn, 2006) and redistributive politics (Laslier, 2002; Roberson, 2008). ${ }^{1}$ However, the predictive power of most of these models has not been tested because of the lack of suitable field data. Laboratory experiments, on the other hand, provide a controlled environment more conducive to collect direct empirical evidence.

This paper reports an experimental investigation of two theoretical models of a multibattle contest by Szentes and Rosenthal (2003, hereafter S\&R) and Konrad and Kovenock (2009, hereafter K\&K). Their common framework captures a contest environment wherein players must allocate a fixed amount of resources over three battles. The player who wins a majority (two out of three battles) wins the contest and gets the prize (minus his bids) while the loser must still pay her bids. Both models assume that the player expending the highest bid wins the individual battle with certainty. The expected level of expenditure in both models is equal to the value of the

\footnotetext{
${ }^{1}$ For the review of the literature see Kovenock and Roberson (2012).
} 
prize, yielding players zero expected payoffs in equilibrium. The models mainly differ in the timing of battles: S\&R captures simultaneous multi-battle contest while $\mathrm{K} \& \mathrm{~K}$ captures sequential multi-battle contest. In case of simultaneous contest, players are predicted to make positive and symmetric bids in all battles, with bids restricted by certain theoretical boundaries. In case of sequential contest, players are predicted to make sizable bids only in the first battle and no bids in the subsequent battles. Contrary to these theoretical predictions, we find that $35 \%$ of the time subjects in simultaneous contests make positive bids in only two, instead of all three, battles and they significantly overuse moderately high bids. Similarly, in sequential contests subjects significantly underbid in the first battle and overbid in subsequent battles. Consequently, instead of always ending in the second battle, $38 \%$ of the time the contest proceeds to the third battle. Finally, in both simultaneous and sequential settings, subjects make higher aggregate bids than predicted resulting in negative expected payoffs.

The theoretical literature on simultaneous multi-battle contests goes back to the original formulation of a Colonel Blotto game by Borel (1921). Colonel Blotto game is an archetype of the strategic multi-dimensional resource allocation problem - players must simultaneously allocate their resource endowment across $n$-battles, with the objective of maximizing the expected number of battles won. In each battle, the player who allocates the highest level of resources wins, and the payoff from the whole contest is contingent on the number of wins across all individual battles (Roberson, 2006; Hart, 2008). The original constant-sum formulation of the game featured "use it or lose it" in the sense that resources which are not allocated to one of the battles are forfeited. Over the years, different variants of the game have been examined to address problems in redistributive politics (Laslier, 2002; Roberson, 2008), military and systems defense (Kovenok and Roberson, 2009; Deck and Sheremeta, 2012), and political campaigns 
(Snyder, 1989; Klumpp and Polborn, 2006). In our study we examine a non-constant-sum formulation with a majoritarian objective payoff function where player's payoff increases in the second battle and then decreases for the third battle. ${ }^{2}$ Szentes and Rosenthal (2003) refer to this as a simultaneous "pure chopstick" auction, where chopsticks are suggestive of identical objects that useless except in pairs.

The theoretical literature on sequential multi-battle contests originated with seminal work by Fudenberg et al. (1983). In their model, two identical firms simultaneously decide how much effort to put in R\&D. After observing the result of the first battle, firms move on to the next battle. Fudenberg et al. find that firm which leads by two or more battles becomes a monopoly and the firm which lags behind drops out of the competition. Subsequent papers have investigated the sequence of the decisions, asymmetry between players, impact of discount factors and intermediate prizes, cf. Harris and Vickers (1985, 1987), Leininger (1991), Budd et al. (1993), Klumpp and Polborn (2006), and Konrad and Kovenock (2009).

In this study we vary the temporal nature of multi-battle contests (simultaneous vs. sequential), but assume that each battle is an all-pay auction with complete information. An allpay auction is a simultaneous move game in which each player must pay his bid (as opposed to winner-pay auction) and the highest bidder wins the contest with certainty (Hillman and Riley, 1989; Baye et al., 1996). In the literature, this is a popular method of modeling environments where outcome is deterministic and not influenced by random exogenous noise. ${ }^{3}$ Theoretical examination of single-battle all-pay auction dates back to Nalebuff and Stiglitz (1983) and Dasgupta (1986), and its applications have been extensively studied for both complete and

\footnotetext{
${ }^{2}$ Other recent extensions of the game include the non-constant-sum formulation with proportional objective (Kvasov, 2007; Roberson and Kvasov, 2012) and asymmetric objective (Kovenock et al., 2010; Deck and Sheremeta, 2012) payoff functions.

${ }^{3}$ An alternative formulation is the "lottery" or Tullock contest (1980) where outcome is probabilistic, i.e. the probability of winning a stage-battle is increasing in player's own bid and decreasing in the other player's bid.
} 
incomplete information. Our multi-battle contest is modeled as a dynamic game similar to sports tournaments and primary elections where each battle is an all-pay auction.

As detailed above, theoretical work on multi-battle contests extends over several decades but experimental investigation in this literature is fairly recent. ${ }^{4}$ There are several recent studies investigating the original simultaneous move constant-sum Colonel Blotto game. Avrahami and Kareev (2009) and Chowdhury et al. (2012) find strong support for the predictions of the original Colonel Blotto game. Unlike these studies, we examine a non-constant-sum version of the simultaneous multi-battle contests and find that individual behavior significantly diverges from theoretical predictions, both quantitatively (in terms of the magnitude of overbidding) and qualitatively (in terms of the strategies used).

Experimental studies on sequential multi-battle contests mostly feature elimination contests wherein players compete within their own groups by expending efforts, and the winner of each group proceeds to the second round (Parco et al., 2005; Amegashie et al., 2007; Sheremeta, 2010; Altmann et al., 2012). There are only a few studies that examine the "best of n” sequential framework similar to ours. Zizzo (2002) studies a patent race similar to Harris and Vickers (1987) and finds that contestants compete more aggressively than predicted. Mago et al. (2011) examine the impact of intermediate prizes and luck on bidding behavior, and Irfanoglu et al. (2011) focus on behavior in sequential versus simultaneous probabilistic contests. However, these studies feature "lottery" contests as opposed to an all-pay auction. Our study is the first to

\footnotetext{
${ }^{4}$ For a comprehensive review of the experimental literature see Sheremeta et al. (2012). The vast majority of experimental studies focus on a single battle contests (Davis and Reilly, 1998; Potters et al., 1998; Gneezy and Smorodinsky, 2006; Lugovskyy et al., 2010). Despite considerable differences in experimental design among these studies, they all find that aggregate expenditure exceeds the equilibrium predictions. Recently, Englmaier et al. (2009) conducted a study on first- and second-price winner-pay multi-object auctions that are somewhat related to the multi-battle contests.
} 
examine bidding behavior in a sequential multi-battle contest with deterministic all-pay contest success function.

The rest of the paper is organized as follows: In Section 2 we briefly describe the theoretical framework and the implied predictions for the experiment. Section 3 details the experimental design and procedures. Section 4 reports the results of the experiment and Section 5 concludes.

\section{Theoretical Model and Predictions}

\subsection{General Model}

Assume that there are two risk-neutral players, $X$ and $Y$, competing in a series of battles for a commonly known prize value $v$. The number of battles is $n=3$. Let $x_{i}$ and $y_{i}$ be the amount of resources (bid) spent by players $X$ and $Y$ in battle $i$. The contest success function is deterministic in the sense that player making the highest bid wins the battle with certainty. To win the overall contest and receive the prize, a player has to win a majority of the battles, i.e. at least $k=(n+1) / 2=2$ battles. The net payoff of $X$ (similarly to $Y$ ) is equal to the value of the prize (if he wins) minus the total bid he has spent during the contest:

$$
\pi_{X}= \begin{cases}v-\sum_{i=1}^{n} x_{i} & \text { if } X \text { wins the contest } \\ -\sum_{i=1}^{n} x_{i} & \text { otherwise }\end{cases}
$$

The battles in the contest proceed either simultaneously or sequentially. In the simultaneous multi-battle contest, players simultaneously choose bids $x_{i}$ and $y_{i}$ for all battles $i=1,2,3$. Then, the winner of each battle is determined and the player who wins at least $k=2$ battles wins the overall contest and obtains the prize. In the sequential multi-battle contest, players simultaneously choose bids $x_{1}$ and $y_{1}$ in battle 1 . After determining the winner of battle 
1 , they move on to battle 2 where they choose $x_{2}$ and $y_{2}$. Players compete until one player has accumulated the required $k=2$ victories.

\subsection{Simultaneous Multi-Battle Contest}

The solution to the simultaneous non-constant-sum multi-battle contest exists only for three battles and can be found in Szentes and Rosenthal (2003) and Kovenock and Roberson (2012). When $k=2$ and $n=3$, there is a unique, symmetric mixed strategy Nash equilibrium. ${ }^{5}$ In the equilibrium, player $X$ makes a draw $\left(x_{1}, x_{2}, x_{3}\right)$ from a uniform probability measure on the three-dimensional surface defined by four points $\left(\frac{v}{2}, \frac{v}{2}, 0\right),\left(\frac{v}{2}, 0, \frac{v}{2}\right),\left(0, \frac{v}{2}, \frac{v}{2}\right)$, and $(0,0,0)$; and then allocates $\left(\left(x_{1}\right)^{2},\left(x_{2}\right)^{2},\left(x_{3}\right)^{2}\right)$ to the three battles according to the joint cumulative distribution function $F\left(\left(x_{1}\right)^{2},\left(x_{2}\right)^{2},\left(x_{3}\right)^{2}\right)=\frac{x_{1} x_{2}}{v}+\frac{x_{1} x_{3}}{v}+\frac{x_{2} x_{3}}{v}-\frac{\left(x_{1}\right)^{2}+\left(x_{2}\right)^{2}+\left(x_{3}\right)^{2}}{2 v}$. The marginal distribution in each battle is given by $F(x)=\sqrt{\frac{2 x}{v}}$ with $x \in\left[0, \frac{v}{2}\right]$. The expected total bid expenditure by both players is equal to the value of the prize; and therefore, in equilibrium, the expected payoff to each player is $E\left(\pi_{X}\right)=E\left(\pi_{Y}\right)=0$.

\subsection{Sequential Multi-Battle Contest}

The solution to the sequential multi-battle contest can be found in Konrad and Kovenock (2009). In contrast to the simultaneous contest, battles proceeds sequentially, and both players simultaneously choose their bids in each battle. Players learn the outcome of the preceding battle before moving to the next battle. Note that the contest can end in two battles if the winner of battle 1 also wins battle 2. In the subgame perfect Nash equilibrium, in battle 1 player $X$

\footnotetext{
${ }^{5}$ Details and derivation of the equilibrium can be found in Kovenock and Roberson (2012).
} 
(similarly $Y$ ) uniformly randomizes according to the distribution function $F(x)=\frac{x}{v}$ with $x \in[0, v]$. The winner of battle 1 then proceeds to win the overall contest with probability one by incurring minimal bid expenditure in battle $2{ }^{6}$ The expected total bid expenditure by both players is equal to the value of the prize; and therefore, in equilibrium, the expected payoff to each player is $E\left(\pi_{X}\right)=E\left(\pi_{Y}\right)=0$. Note that sequential multi-battle contest of K\&K is behaviorally similar to a single battle all-pay auction.

\section{Experimental Design and Procedures}

Within the multi-battle contest framework, we employ two treatments: sequential and simultaneous. In the simultaneous treatment, two players simultaneously decide on their bidding strategy across three battles, and the player who wins two battles wins the contest. In the sequential treatment, two players compete in a sequence of battles, and the first player to win two battles wins the contest. For our chosen parameters, the theoretical prediction for both treatments is shown in Table 1.

We ran a total of six experimental sessions (three for each treatment). Each session had 12 subjects, all of whom were volunteers recruited from undergraduate student population at Chapman University. No subject participated in more than one session, although some had participated in other economics experiments that were unrelated to this research. The computerized experimental sessions were programmed using z-Tree (Fischbacher, 2007).

\footnotetext{
${ }^{6}$ The reason for minimal expenditure in battle 2 is as follows: In battle 1, players are symmetric in terms of the continuation values for the next battle, but in battle 2, the winner of battle 1 still has a strictly positive continuation value and the loser's continuation value goes down to zero. Since the loser has no incentive to compete in battle 2 , he makes a bid of zero. K\&K assume in case of a tie in bid expenditures, winner is the player with a higher continuation value. This implies that the winner of battle 1 wins battle 2 and is the overall contest winner without incurring any additional bid expenditure. In our experiment, however, we assume that ties in all battles are determined by random coin flip. This implies that in battle 2, the winner of battle 1 should outbid the loser by "an epsilon” (see footnote 17 in K\&K).
} 
Throughout the session no communication between subjects was permitted and all choices and information were transmitted via computer terminals. All decisions were anonymous. Subjects were given the instructions, available in the Appendix, and the experimenter read the instructions aloud as subjects followed along on paper. ${ }^{7}$ Before the actual experiment, subjects completed an online questionnaire that tested their comprehension of the instructions. The experiment started only after all subjects had answered the quiz questions, and explanations were provided for any incorrect answers.

Each experimental session corresponded to 20 periods of play in one of the two treatments. In every period, subjects were randomly and anonymously placed into 6 groups with 2 players in each group. It was common knowledge that the valuation of prize was identical across all bidders and equal to 100 francs. Subjects were not allowed to bid more than 100 francs in any battle and were informed that regardless of who wins the contest, all subjects would have to pay their bids. Subjects were also instructed that in each battle the bidder with the higher bid wins, and in case of a tie, winner is determined by a random coin flip. In the simultaneous treatment subjects were asked to make bids in each of the 3 battles simultaneously. ${ }^{8}$ After subjects submitted their bids, the computer displayed own bid, the opponent's bid, the winner of each battle, the overall contest winner and the individual earnings that period. In the sequential treatment subjects participated either in two or three battles. At the end of each battle, the computer displayed own bid, the opponent's bid, the winner of that battle. The period ended when one of the subjects in the group won two battles. At the end of each period subjects were

\footnotetext{
${ }^{7}$ Before the start of the experiment we also elicited subjects' risk preferences by utilizing a series of 15 lottery choices, similar to Holt and Laury (2002).

${ }^{8}$ To keep the terminology neutral, in the instructions we describe the task as allocating tokens to three different boxes.
} 
randomly re-grouped to form a new 2-player group. The instructions explained the structure of the game in detail using a number of illustrative examples.

At the end of the experiment, 2 out of 20 periods were randomly selected for payment. The sum of the earnings for these 2 periods was exchanged at rate of 25 francs $=\$ 1$. Additionally, all subjects received an initial endowment of \$20 to cover potential losses. On average, subjects earned \$21 each, which was paid anonymously and in cash, and earnings varied between $\$ 14$ and \$29. The experimental sessions lasted for about 60 minutes.

\section{Results}

\subsection{Aggregate Results}

Table 1 summarizes the equilibrium predictions and the aggregate results of the experiment. First notable feature of the data is that there is strong aggregate overbidding in both treatments. The average total bid in the simultaneous treatment (69.2) and in the sequential treatment (59.6) is significantly higher than the theoretical prediction (50.0). ${ }^{9}$ Such significant overbidding is not uncommon in experimental literature on contests and all-pay auctions (Davis and Reilly, 1998; Potters et al., 1998; Gneezy and Smorodinsky, 2006; Sheremeta, 2010, 2011). Moreover, we find that aggregate overbidding does not decrease over time. Figures 1 and 2 indicate that there is no declining trend over 20 periods of experiment. ${ }^{10}$

Finding 1: Average total bid in the simultaneous and sequential contests is significantly higher than predicted.

\footnotetext{
${ }^{9}$ A standard Wald test, conducted on estimates of panel regression models, rejects the hypothesis that the average total bids in the simultaneous and sequential treatments are equal to the predicted theoretical value of 50 (both pvalues $<0.01$ ). The panel regression models included a subject level random effects error structure to account for the multiple efforts made by individual subjects. The standard errors were also clustered at the session level to account for session effects.

${ }^{10}$ The coefficient on the time trend variable indicates that bids increase in the sequential treatment ( $\mathrm{p}$-value $\left.=0.02\right)$ and do not decrease in simultaneous treatment $(\mathrm{p}$-value $=0.3$ ).
} 
As a result of this persistent overbidding, subjects on average earn negative payoffs (i.e., -19.5 in simultaneous and -9.6 in sequential treatment). One explanation for this payoff result is based on the 'exposure problem' that confronts players in a multi-battle contest. Informally, the problem occurs when a player aims to win a set of objects that have synergies and bids more than the stand-alone valuation of a single object in the hope of obtaining extra value through synergy gained from winning the entire set. In our experiment, synergies across multiple battles emerge from the majority rule (wining 2 out of 3 battles). Exposure problem has been widely studied in multi-unit sequential and simultaneous FCC spectrum auctions (Englmaier et al., 2009; Van Damme, 2002; Cramton, 1997). Furthermore, although the problem exists irrespective of the temporal design detail (simultaneous or sequential), one can conjecture that sequential contests soften the exposure problem by allowing players to assess the likelihood of successfully acquiring the entire set of objects at each stage (Ausubel and Cramton, 2006). Accordingly, we also find that the level of overdissipation is higher in simultaneous contests as opposed to sequential contests (69.2 vs. 59.6, p-value < 0.01).

Finding 2: The level of aggregate dissipation is higher in simultaneous contests.

To further elaborate on the overbidding behavior, following Baye et al. (1999), we employ two concepts of overdissipation. Baye et al. define aggregate overdissipation as the sum of bids by both players being greater than the value of the prize, and individual overdissipation as sum of bids by a single player being greater than the value of the prize. In both treatments, mixed strategy Nash equilibrium precludes the possibility of overdissipation in expectation: equilibrium aggregate dissipation is equal to the value of the prize (100), and there is no individual overdissipation since any bid greater than 100 would guarantee a negative payoff. However, since equilibrium involves nondegenerate mixed strategies, for particular realizations 
of the players' mixed strategies, aggregate bids may exceed the value of the prize. That is, the game exhibits probabilistic aggregate overdissipation. Baye et al. (1999) show that for a singlebattle all-pay auction, the probability of aggregate overdissipation ranges from 0.5 to 0.44 as the number of players increases from two to infinity. In conflict with these equilibrium forecasts, Gneezy and Smorodinsky (2005) and Lugovskyy et al. (2010) find aggregate overdissipation at 0.84 and 0.88 respectively. In our experiment, the incidence of aggregate overdissipation is similar to these findings -0.83 in simultaneous treatment and 0.62 in sequential treatment. The level of average aggregate overdissipation is $38.3 \%$ in the simultaneous treatment and $19.2 \%$ in the sequential treatment (can also be roughly inferred from Figures 1 and 2). Finally note that probabilistic individual overdissipation is a dominated strategy since a player can guarantee a payoff of at least zero by bidding zero. Accordingly, in both treatments we find few sporadic incidences where individual players bid more than the prize value of 100 (0.02 in simultaneous treatment and 0.07 in sequential treatment). ${ }^{11}$

\subsection{Simultaneous Contest}

Theoretical prediction for simultaneous contest is that in each battle players should randomize between 0 and 50 according to the cumulative distribution function $F(x)=\sqrt{\frac{x}{50}}$, with an average bid of 16.7 in each battle. Figure 3 shows that aggregate behavior largely conforms to the equilibrium predictions. In all three battles, the interval over which subjects randomize is

\footnotetext{
${ }^{11}$ Most of these incidences are subject specific. For example, in the simultaneous treatment, one subject is responsible for a third of the documented individual overdissipation. Our results are comparable to Gneezy and Smorodinsky (2006) who report incidence of individual overdissipation at 0.1. Possible explanations for such seemingly "irrational” behavior include mistakes and non-monetary utility of winning (Sheremeta, 2010, 2011; Price and Sheremeta, 2011).
} 
between 0 and 50 with less than $5 \%$ of bids above 50 . The overall distribution of bids is also remarkably similar in the three battles.

Finding 3: In the simultaneous contest, bids fall within the predicted boundaries.

Although the main qualitative predictions of S\&R model are supported, there are several interesting behavioral deviations from the theory. One, as mentioned above, there is significant overbidding, with bid in each battle averaging at 23.1 (compared to the predicted level of 16.7). Subjects overuse moderately high bids. Figure 3 notes that instead of a concave distribution, bids are distributed according to a convex/linear cumulative distribution function. Second, contrary to the theory, players do not employ 'stochastic complete coverage.' Figure 3 indicates that there is a mass point at 0 in each of the 3 battles, suggesting that subjects do not make any bids in a given battle around $20 \%$ of the time. A closer look at the individual data shows that subjects make positive bids in all three battles only 62\% of the time (instead of 100\%), and they make positive bids in two out of three battles 35\% of the time (instead of $0 \%$ ).

Finding 4: In the simultaneous contest, $35 \%$ of the time subjects make positive bids in only two out of three battles (instead of all three) and they significantly overuse moderately high bids.

It is important to emphasize, that such non-optimal behavior is very costly. Given that others bid 0 in some battles, one can substantially increase the chance of winning by simply making a very cheap bid of 0.1 franc. Therefore, error-based behavioral models, such as quantal response equilibrium (McKelvey and Palfrey, 1995), would not be a good explanation for Finding 4. However, while it is clear that subjects do not behave in strict accordance with the theoretical predictions, the type of behavior described in Finding 4 can be explained by a 'guerilla warfare' strategy found in experiments on Blotto-type games (Kovenock et al., 2010; 
Chowdhury et al., 2012; Deck and Sheremeta, 2012). Kovenock et al. (2010), for example, report behavior consistent with guerilla strategies in the simultaneous weakest-link contest. They find that when the objective for one of the players (attacker) is to win only one battle, then such a player utilizes a stochastic 'guerilla warfare' strategy, by attacking single battle $80 \%$ of the time (even when such behavior is not predicted by the theory). In a multi-battle contest, to win the overall contest, each player needs to win only two out of three battles. This entails that players may randomly select and focus their bid expenditure on just two battles. This also helps mitigate the 'exposure problem' described in the previous section. Overall, the choice of the number of battles is very individual specific. We find that $61 \%$ of the subjects can be defined as "equilibrium bidders" and 28\% as "guerilla bidders."12

We find that the probability of winning when subjects make positive bids in only 2 battles is 0.58 and when they make positive bids in all 3 battles is 0.48 . This difference in the likelihood of winning is statistically significant (p-value $<0.01$ ). Despite this, however, aggregate dissipation rate is remarkably similar whether subjects bid in all 3 or in the chosen 2 battles (p-value $=0.37$ ). Average total bid across 3 battles is 69.2 and across 2 battles is 75.2 . This incongruity is explained by the fact that even when subjects make positive bids in all 3 battles, minimum bid is less than or equal to 1 about $40 \%$ of the time. Interestingly enough, $59 \%$ of the time when subjects employ 'guerilla warfare' strategy they choose the same bid across the two battles.

\footnotetext{
${ }^{12}$ We define "equilibrium bidders" as subjects who allocate their resources across all three battles more than $60 \%$ of the time (12 or more periods out of 20) and "guerilla bidders" as subjects who more likely to focus their attention on 2 battles.
} 


\subsection{Sequential Contest}

Next we analyze individual behavior in the sequential contest. The theoretical prediction of K\&K model is clearly rejected by the data, for all three battles. In battle 1 , theory predicts that each player should uniformly randomize between 0 and 100, with an expected average bid of 50 . Instead, subjects on average bid 16.7 in battle 1 (Table 1). Moreover, from Figure 4, it is clear that instead of a uniform distribution between 0 and 100, there are virtually no bids above 50 (less than $1 \%$ of bids are above 50 ). In battle 2 , theory predicts that the loser of battle 1 should bid 0 and the winner should bid 0.1 (an "epsilon”). This theoretical prediction is also rejected by the data. Instead of bidding zero, loser of battle 1 bids 24.7, while winner of battle 1 bids 34.0. ${ }^{13}$ Finally, the subgame perfect equilibrium for battle 3 is equivalent to a simple all-pay auction with two symmetric players (since both players have won one battle each). Therefore, the equilibrium strategy in battle 3 is to randomize uniformly between 0 and 100, with the expected average bid of 50. Figure 4 shows that, instead, subjects randomize between 0 and 70 , with the average bid of 35.7. Overall, contrary to prediction, bids in battles 2 and 3 are significantly higher than the bid in battle 1 (p-value $<0.01$ ). ${ }^{14}$

Finding 5: In the sequential contest, subjects significantly underbid in the first battle and make significantly higher bids in the subsequent battles.

Note that in equilibrium, the sequential contest should never proceed to battle 3 . This is because the loser of battle 1 should give up in battle 2, and thus the winner of battle 1 should win

\footnotetext{
${ }^{13}$ The observation that the bid by battle 1 winner is significantly higher than that of the loser (p-value $<0.01$ ) may be rationalized by "strategic momentum," as in Mago et al. (2011).

${ }^{14}$ We estimated two panel regression models, where the dependent variable is the bid and the independent variables are a period trend and a dummy-variable for battle 2 (or 3). The panel regressions included a random effects error structure, with the individual subject as the random effect, to account for the multiple efforts made by individual subjects. The standard errors were clustered at the session level to account for session effects. The estimation results show that the dummy-variable is positive and significant for both battles 2 and 3 (p-value $<0.01$ ). When comparing bids in battle 1 and battle 2, we used all observations. However, when comparing bids in battle 1 and battle 3, we used only those observations where contest ended in three battles.
} 
battle 2 with probability one. However, Finding 5 indicates that the major competition happens not in battle 1, but in the subsequent battles. As a result, the contest proceeds to the third battle $38 \%$ of the time, instead of predicted $0 \%$. Figure 2 displays the average bid in each battle over 20 periods of the experiment. It appears that the aggregate pattern of behavior does not change with experience. Moreover, in all periods, the bidding expenditure profile features a "hold-up": successful participation in later battles requires substantial bids, and this makes it less attractive to allocate higher bids in the preliminary battles.

Finding 6: In the sequential contest, instead of ending the contest in the second battle, contest proceeds to the third battle $38 \%$ of the time.

Theory also predicts that the winner of battle 1 wins the overall contest with absolute certainty. We find that the probability of battle 1 winner winning the overall contest is 0.8 , which is significantly lower than the theoretical prediction of 1 (p-value $<0.01$ ). This can be explained by the fact that the distribution of bids in battle 2 for the winner and the loser of battle 1 are quite similar (Figure 4). More importantly, we observe that loss in battle 1 does not discourage the loser and he continues to bid positive amount in battle 2. Consequently, battle 1 winner continues his winning streak in battle 2 only $62 \%$ of time. In battle 3 , theory predicts that both players are equally likely to win, and indeed, we find that winner of battle 1 wins the third battle $48 \%$ of the time.

Finding 7: In the sequential contest, the likelihood of the winner of the first battle winning the overall contest is significantly less than predicted.

Findings 5-7 indicate that the behavior of subjects in the sequential contest poses a challenge to the theoretical predictions of K\&K model. One conjecture is that although subjects do not behave according to the subgame perfect equilibrium, they may still act optimally in each 
stage-battle. Employing backward induction, consider that average bid in battle 3 is 35.7. This implies that subject's expected payoff from the third battle is positive $(0.5 * 100-35.7=14.3)$ and therefore, positive bid in the second battle are not entirely irrational. The extent of actual overbidding, however, is quite substantial. In the data, we find that $87 \%$ of the sum of bids in battles 1 and 2 are more than 14.3. Even focusing solely on battle 2, 74\% of the bids exceed the rationalizable threshold of 14.3. Similiarly, if we assume that subjects have correct expectation about the competition in battles 2 and 3, then they should not bid as much as predicted by the theory in battle 1 . Since the average sum of bids in battles 2 and 3 is 42.9, it follows that subjects in battle 1 should behave as if the expected payoff was $7.1(100 \times 0.5-42.9=7.1)$. Again, we find that bids in battle 1 exceeding the rationalizable threshold of 7.1 account for $69.2 \%$ of the observations.

Another explanation for overdissipation is that subjects derive a non-monetary utility of winning (Sheremeta, 2010; Price and Sheremeta, 2011). Based on the assumption that subjects care only about their monetary prize, standard equilibrium theory predicts that battle 1 loser will suffer from a dramatic decrease in his continuation value for the next battle, and accordingly will not bid in battle 2. However, if we incorporate winning as a component in the subject's utility function, the decline in continuation value for battle 2 is not so dramatic. Loser of battle 1 not only has a non-monetary utility of winning battle 2, but may also expect to receive an additional utility from a possible win in battle 3 . Such a contest, therefore, inherently transforms into a multi-battle sequential contest with intermediate prizes; and one of the fundamental theoretical results in the sequential contest with intermediate prizes is that "the player who is lagging behind may catch up, and does catch up with a considerable probability in the equilibrium” (Konrad and 
Kovenock, 2009, page 267). ${ }^{15}$ This explanation is consistent with our finding that the loser of battle 1 makes positive bid in battle 2, and in fact wins the overall contest $20 \%$ of the time.

Finally, sunk cost fallacy may also explain part of the overdissipation in sequential contests. The payoff maximization exercise underlying the equilibrium in multi-battle sequential contest regards expenditure in previous battles as sunk cost, and therefore ignores them. Evidence from various behavioral studies, however, suggests otherwise (Arkes and Blumer, 1985; Friedman et al. 2010). In our experiment, we do not find any evidence of overbidding in battle 3 but it would be wrong to view this isolation from the previous bidding behavior. Subjects who get to battle 3 have already made positive bids in the previous two battles. We can therefore compute the "empirical rationalizable bid" in battle 3 using individual subject data for the previous two battles. Specifically, this rationalizable bid, $r$, is the difference between the expected prize of 50 and the bids already incurred in battles 1 and 2. Under the null hypothesis (using the premise of no individual overdissipation), subjects should not bid greater than $r$ in battle 3. However, under the alternate "sunk cost" hypothesis, subjects who make larger bids in battles 1 and 2 are also more likely to bid amounts greater than $r$ in the final decisive battle. In our data, the value of $r$ ranges from -46 to 50, with a mean of 4.4 and standard deviation of 21.5. We find that $87.6 \%$ of the time subjects' bids in battle 3 are greater than the rationalizable bid $r$. A simple random effect regression shows that there is a positive and marginally significant relationship between actual bid and rationalizable bid in battle 3 (p-value $=0.08)$. Therefore, sunk cost may also partially account for overdissipation in the later stages of the sequential multi-battle contest.

\footnotetext{
${ }^{15}$ In an experimental test of multi-battle contests with lottery success function, Mago et al. (2011) also find that intermediate prizes not only lead to significantly higher dissipation by both players, but also reduce the probability of the contest ending in 2 rounds.
} 


\section{Conclusion}

This paper examines behavior of subjects in simultaneous and sequential multi-battle contests where each component battle is an all-pay auction with complete information. Our experiment provides some support to the qualitative predictions of Szentes and Rosenthal (2003) model of simultaneous contest, i.e. bids fall within the predicted boundaries. However, instead of the 'complete stochastic coverage' strategy, subjects employ the 'guerilla warfare' strategy by having a significant mass point at zero in each battle. Specifically, 35\% of the time subjects make positive bids in only two out of three battles (instead of all three) and also significantly overuse moderately high bids. In case of sequential contest, data are clearly inconsistent with the prediction of Konrad and Kovenock (2009) model. Theory predicts sizable bids in the first battle and no bids in the subsequent battles. Contrary to this prediction, subjects significantly underbid in the first battle and make substantially higher bids in the subsequent battles. As the result, instead of always ending in the second battle, contest proceeds to the third battle $38 \%$ of the time. Finally, in both simultaneous and sequential settings, subjects make higher aggregate bids than predicted resulting in negative expected payoffs.

Multi-battle contests are prevalent in many real life situations and are readily applicable to a number of important strategic environments (e.g., multi-unit auctions, R\&D and patent races, network security, conflicts, sports championship series, elections, redistributive politics). Therefore, it is hardly surprising that there has been an increased interest in the literature on multi-battle contests and many significant theoretical advancements have been made over the past decade by prominent scholars across a range of disciplines. ${ }^{16}$ The predictive power of most of these models, however, has not been tested because of paucity of suitable field data. Our

\footnotetext{
${ }^{16}$ To name a few contributions over the past decade: Szentes and Rosenthal (2003), Klumpp and Polborn (2006), Roberson (2006, 2008), Kvasov (2007), Hart (2008), Hausken, (2008), Konrad and Kovenock (2009), Levitin and Hausken (2010), Golman and Page (2009), Roberson and Kvasov (2012).
} 
experimental findings emphasize the importance of empirical investigation of theoretical models of multi-battle contests. We find that, although neither model of the multi-battle contest predicts individual behavior accurately, qualitatively speaking, the static model of Szentes and Rosenthal (2003) is a better predictor than the dynamic model of Konrad and Kovenock (2009). We believe that this discrepancy in predictive power might be of interest to contest designers - both theorists and practitioners in the field. We identify possible behavioral explanations for the lack of support for the equilibrium predictions of each model. Future theoretical research should focus on how to incorporate these behavioral considerations into formal models of multi-battle contests.

Our findings also contribute to the recent studies investigating behavior in Colonel Blotto games (cf., Avrahami and Kareev, 2009; Arad and Rubinstein, 2009; Chowdhury et al., 2012). Unlike these studies, which find strong support for theory, we find that individual behavior significantly diverges from the theoretical predictions, both quantitatively (in terms of the magnitude of overbidding) and qualitatively (in terms of the strategies used). A possible explanation for these differences is that we examine non-constant-sum multi-battle contests which allow for overdissipation, while Colonel Blotto game studies examine constant-sum multibattle contests where resource allocation is restricted. Another explanation is that we examine a majoritarian objective function (i.e., the player winning the best of three battles wins the overall contest), while Colonel Blotto game studies examine proportional objective function (i.e., each battle has its separate reward). Whether it is the non-constant-sum nature or the majoritarian objective function that drives the difference between our findings and the findings of previous Colonel Blotto game studies is an interesting question for future research.

Our experiment points out several fruitful avenues for future research. First, as mentioned above, it is important to incorporate behavioral considerations that would produce the 'guerilla 
warfare' strategy, instead of the 'complete stochastic coverage' strategy, as an equilibrium strategy in multi-battle contests. Second, the solution to simultaneous non-constant-sum multibattle contest exists only for three battles (Szentes and Rosenthal, 2003; Kovenock and Roberson, 2012). One can conduct an experiment with more than three battles and use the results to guide the theory in finding the equilibrium solution. After all, theory and experiments should be seen as compliments in explaining individual behavior and can be effectively "combined to the benefit of both” (Samuelson, 2005). 


\section{References}

Altmann, S., Falk, A. Wibral, M. (2012). Promotions and Incentives: The Case of Multi-Stage Elimination Tournaments. Journal of Labor Economics, 30, 149-174.

Amegashie, J.A., Cadsby, C.B., \& Song, Y. (2007). Competitive burnout: Theory and experimental evidence. Games and Economic Behavior, 59, 213-239.

Arad, A., \& Rubinstein, A. (2009). Colonel Blotto's Top Secret Files. Tel Aviv University, Working Paper.

Arkes, H.R., \& Blumer, C. (1985). The psychology of sunk cost. Organizational Behavior and Human Decision Processes. 35, 124-140.

Ausubel, L. and Cramton, P. (2006). Dynamic Auctions in Procurement. In Nicola Dimitri, Gustavo Piga, and Giancarlo Spagnolo (Eds.) Handbook of Procurement, Cambridge, England: Cambridge University Press.

Avrahami, J., \& Kareev, Y. (2009). Do the Weak Stand a Chance? Distribution of Resources in a Competitive Environment. Cognitive Science, 33, 940-950.

Baye, M., Kovenock, D., \& de-Vries, C.G. (1996). The all-pay auction with complete information. Economic Theory, 8, 291-305.

Baye, M., Kovenock, D., \& de-Vries, C.G. (1999). The Incidence of Overdissipation in RentSeeking Contests. Public Choice, 99, 439-454.

Borel, E. (1921). La theorie du jeu les equations integrales a noyau symetrique. Comptes Rendus del Academie. 173, 1304-1308; English translation by Savage, L. (1953). The theory of play and integral equations with skew symmetric kernels. Econometrica, 21, 97-100.

Budd, C., Harris, C., \& Vickers, J. (1993). A model of the evolution of duopoly: does the asymmetry between firms tend to increase or decrease? Review of Economic Studies, 60, 543-573.

Chowdhury, S.M., Kovenock, D., \& Sheremeta, R.M. (2012). An Experimental Investigation of Colonel Blotto Games. Economic Theory, forthcoming.

Cramton, P. (1997). The FCC Spectrum Auctions: An Early Assessment. Journal of Economics and Management Strategy, 63, 431-495.

Davis, D., \& Reilly, R. (1998). Do too many cooks spoil the stew? An experimental Analysis of rent-seeking and the role of a strategic buyer. Public Choice, 95, $89-115$.

Deck, C., \& Sheremeta, R.M. (2012). Fight or Flight? Defending Against Sequential Attacks in the Game of Siege. Journal of Conflict Resolution, forthcoming.

Englmaier, F., Guillén, P., Llorente, L., Onderstal, S., \& Sausgruber, R. (2009). The chopstick auction: A study of the exposure problem in multi-unit auctions. International Journal of Industrial Organization, 27, 286-291.

Fischbacher, U. (2007). z-Tree: Zurich Toolbox for Ready-Made Economic Experiments. Experimental Economics, 10, 171-178.

Friedman, D., Pommerenke, K., Lukose, R., Milam, G., and Huberman, B.A. (2010) In search for the sunk cost fallacy. Experimental Economics, 10, 79-104

Friedman, L. (1958). Game-theory Models in the Allocation of Advertising Expenditure, Operations Research, 6, 699-709.

Fudenberg, D., Gilbert, R., Stiglitz, J., \& Tirole, J. (1983). Preemption, leapfrogging and competition in patent races. European Economic Review, 22, 3-31.

Gneezy, U., \& Smorodinsky, R. (2006) All-pay auctions - an experimental study. Journal of Economic Behavior and Organization, 61, 255 - 275. 
Golman, R., \& Page, S.E. (2009). General Blotto: Games of Strategic Allocative Mismatch. Public Choice, 138, 279-299.

Harris, C., \& Vickers, J. (1985). Perfect equilibrium in a model of a race. Review of Economic Studies, 52, 193-209.

Harris, C., \& Vickers, J. (1987). Racing with uncertainty. Review of Economic Studies, 54, 1-21.

Hart, S. (2008). Discrete Colonel Blotto and General Lotto Games. International Journal of Game Theory, 36, 441-460.

Hausken, K. (2008). Whether to Attack a Terrorist's Resource Stock Today or Tomorrow. Games and Economic Behavior 64, 2, 548-564.

Hillman, A. \& Riley, J.G. (1989). Politically contestable rents and transfers. Economics and Politics, 1, 17-40.

Holt, C.A. \& Laury, S.K. (2002). Risk Aversion and Incentive Effects. American Economic Review, 92, 1644-1655.

Irfanoglu, B., Mago, S.D., \& Sheremeta, R.M. (2011). Sequential versus Simultaneous Election Contests: An Experimental Study. Working Paper.

Klumpp, T., \& Polborn, M.K. (2006). Primaries and the New Hampshire effect. Journal of Public Economics, 90, 1073-1114.

Konrad, K.A., \& Kovenock, D. (2009). Multi-battle contests. Games and Economic Behavior, 66, 256-274.

Kovenock, D., \& Roberson, B. (2012). Conflicts with Multiple Battlefields. In Michelle R. Garfinkel and Stergios Skaperdas, (Eds.), Oxford Handbook of the Economics of Peace and Conflict.

Kovenock, D., Roberson, B., \& Sheremeta, R.M. (2010). The Attack and Defense of WeakestLink Networks, Chapman University, Working Paper.

Kvasov, D. (2007). Contests with limited resources. Journal of Economic Theory, 136, 738-748.

Laslier, J.F. (2002). How Two-Party Competition Treats Minorities. Review of Economic Design, 7, 297-307.

Leininger, W. (1991). Patent competition, rent dissipation, and the persistence of monopoly: the role of research budgets. Journal of Economic Theory, 53, 146-172.

Levitin, G. \& Hausken, K. (2010). Resource Distribution in Multiple Attacks Against a Single Target. Risk Analysis, 30, 1231-1239.

Lugovskyy, V., Puzzello, D., \& Tucker, S. (2010). An Experimental Investigation of Overdissipation in the All Pay Auction. European Economic Review, 54, 974-997.

Mago, S.D., Sheremeta, R.M., \& Yates, A. (2011). Best of Three Contests: Experimental Evidence. Working Paper.

McKelvey, R., \& Palfrey, T. (1995), Quantal Response Equilibria for Normal Form Games. Games and Economic Behavior, 10, 6-38.

Parco J., Rapoport A., \& Amaldoss W. (2005). Two-Stage Contests with Budget Constraints: An Experimental Study. Journal of Mathematical Psychology, 49, 320-338.

Potters, J., de Vries, C.G., \& Van Winder, F. (1998). An experimental examination of rational rent-seeking. European Journal of Political Economy, 14, 783 - 800.

Price, C.R., \& Sheremeta, R.M. (2011). Endowment Effects in Contests. Economics Letters, 111, 217-219.

Roberson, B. \& D. Kvasov (2012). The Non-Constant Sum Colonel Blotto Game. Economic Theory, forthcoming.

Roberson, B. (2006). The Colonel Blotto Game. Economic Theory, 29, 1-24. 
Roberson, B. (2008). Pork-Barrel Politics, Targetable Policies, and Fiscal Federalism. Journal of the European Economic Association, 6, 819-844.

Samuelson, L. (2005). Economic Theory and Experimental Economics. Journal of Economic Literature, 43, 65-107.

Sheremeta, R.M. (2010). Experimental Comparison of Multi-Stage and One-Stage Contests. Games and Economic Behavior, 68, 731-747.

Sheremeta, R.M. (2011). Contest Design: An Experimental Investigation. Economic Inquiry, 49, 573-590.

Sheremeta, R.M., Dechenaux, E., \& Kovenock, D. (2012). A Survey of Experimental Findings on Contests, All-Pay Auctions and Tournaments. ESI Working Paper.

Snyder, J.M. (1989). Election Goals and the Allocation of Campaign Resources. Econometrica, 57, 637-660.

Szentes, B., \& Rosenthal, R.W. (2003). Three-object two-bidder simultaneous auctions: chopsticks and tetrahedra. Games and Economic Behavior 44, 114-133.

Tullock, G. (1980). Efficient Rent Seeking. In James M. Buchanan, Robert D. Tollison, Gordon Tullock, (Eds.), Toward a theory of the rent-seeking society. College Station, TX: Texas A\&M University Press, 97-112.

Van Damme, E. (2002). The European UMTS-auctions. European Economic Review 46, 846 869.

Zizzo, D.J. (2002). Racing with Uncertainty: A Patent Race Experiment. International Journal of Industrial Organization, 20, 877-902. 


\section{Table 1: Equilibrium Predictions and Aggregate Statistics}

\begin{tabular}{l|cc|cc}
\hline \hline Treatments & \multicolumn{2}{|c|}{ Sequential } & \multicolumn{2}{c}{ Simultaneous } \\
\hline Prize, $v$ & \multicolumn{2}{|c|}{100} & \multicolumn{2}{c}{100} \\
Number of battles, $n$ & \multicolumn{2}{|c|}{3} & \multicolumn{2}{c}{3} \\
\hline & Equilibrium & Actual & Equilibrium & Actual \\
\hline Expected bid in B1 & 50.0 & $16.7(0.5)$ & 16.7 & $24.4(0.6)$ \\
Expected bid in B2 by B1 winner & 0.1 & $34.0(1.0)$ & 16.7 & $22.8(0.6)$ \\
Expected bid in B2 by B1 loser & 0.0 & $24.7(1.0)$ & - & - \\
Expected bid in B3 & 50.0 & $35.7(1.0)$ & 16.7 & $21.9(0.6)$ \\
The probability of ending in B2 & 1.0 & $0.62(0.02)$ & - & - \\
Expected average total bid & 50.0 & $59.6(1.3)$ & 50.0 & $69.2(0.9)$ \\
Expected payoff & 0.0 & $-9.6(1.8)$ & 0.0 & $-19.15(1.7)$ \\
\hline
\end{tabular}

Standard error of the mean is in parenthesis.

We do not find a difference between expected bid in B3 by winners and losers of B2.

Therefore, we combine the data for the bids in B3. 
Figure 1: Bids across All Periods in Simultaneous Treatment

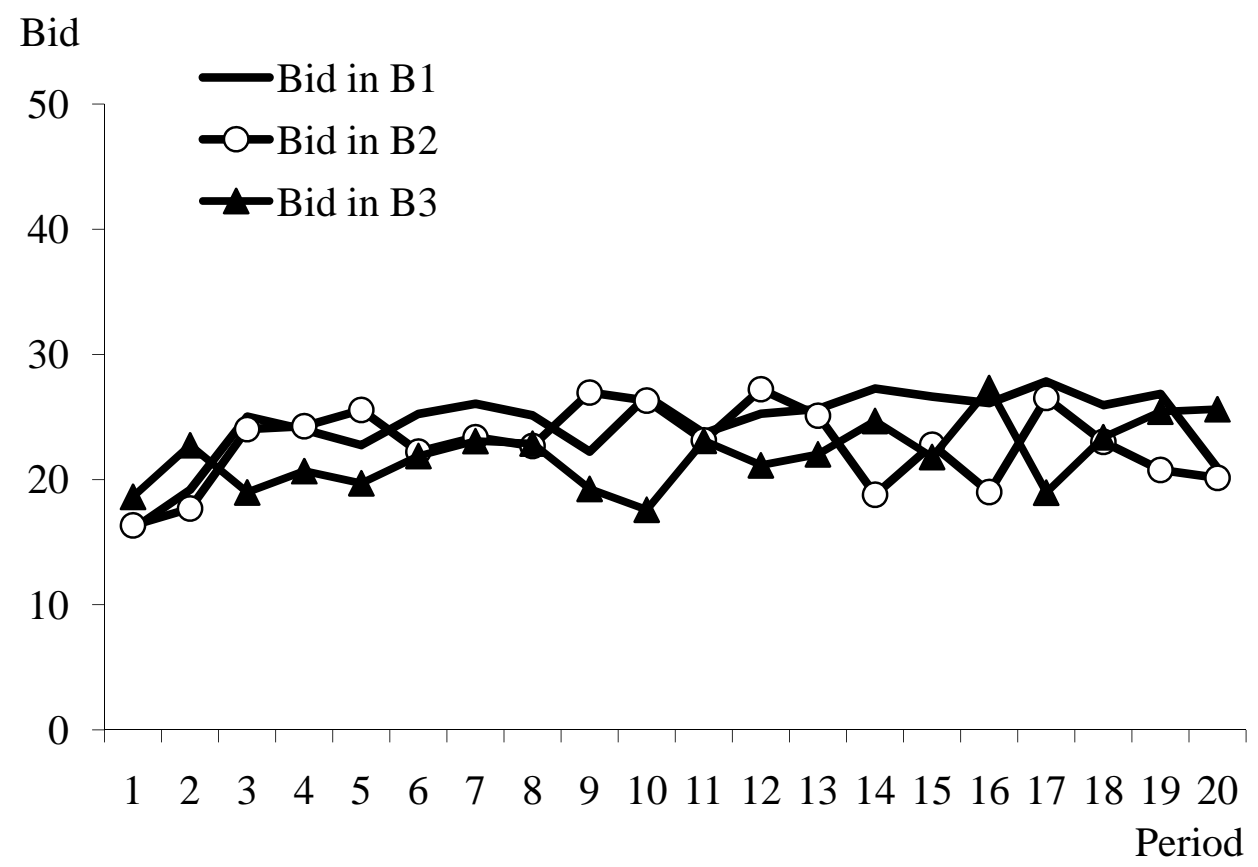

Figure 2: Bids across All Periods in Sequential Treatment

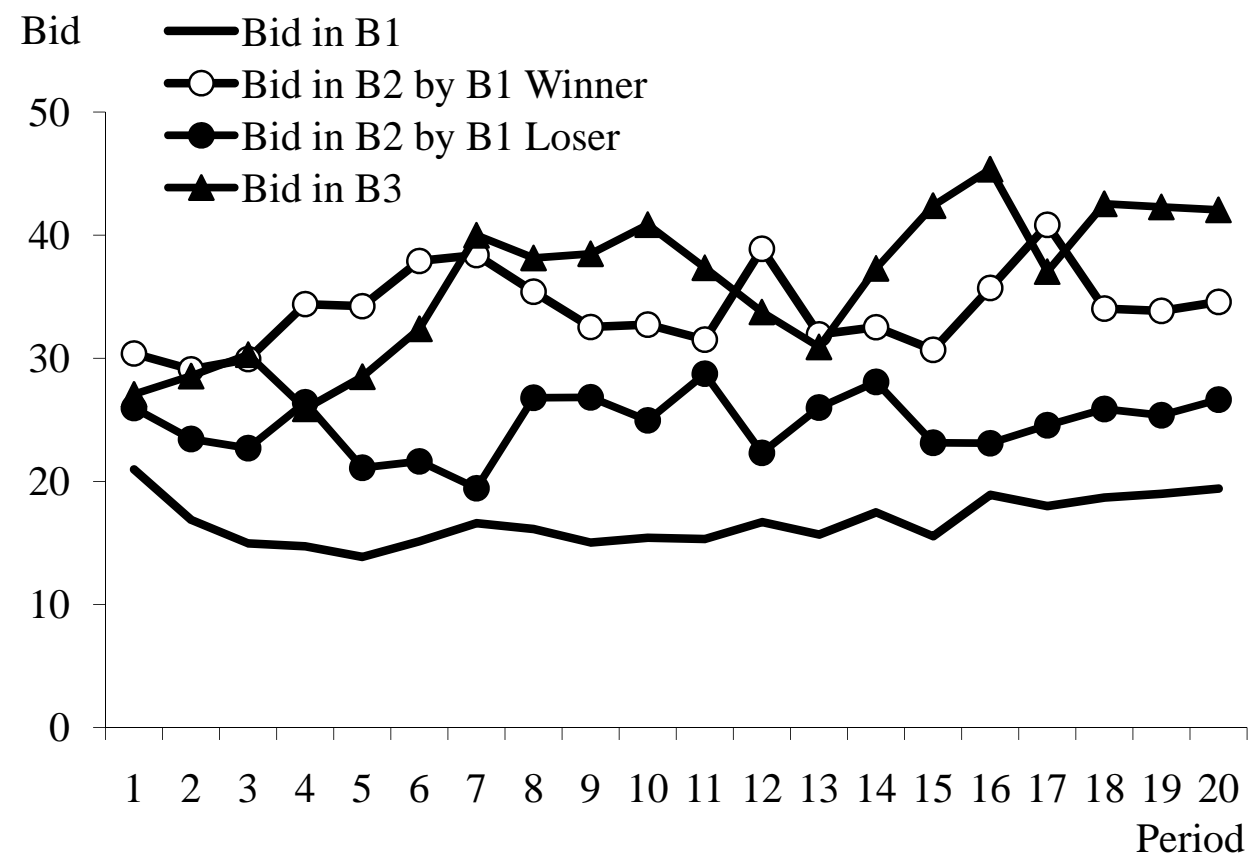


Figure 3: Distribution of Bids in Simultaneous Treatment
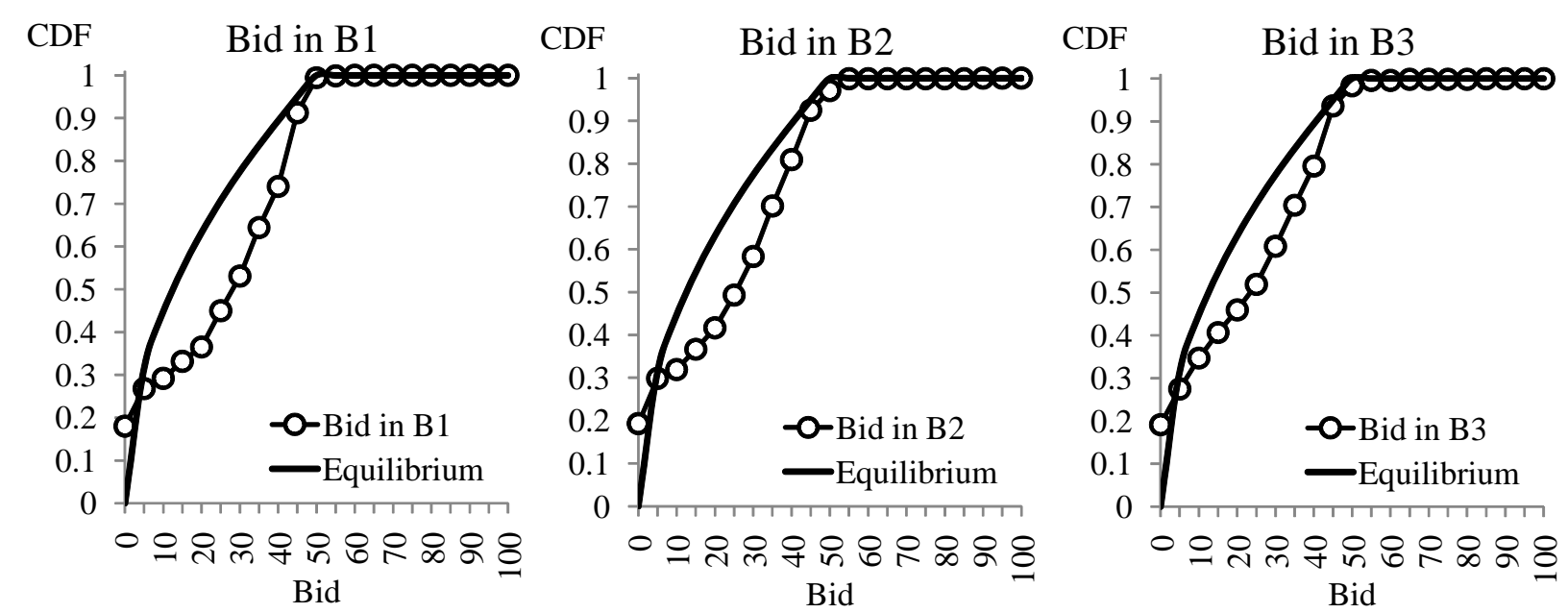

Figure 4: Distribution of Bids in Sequential Treatment
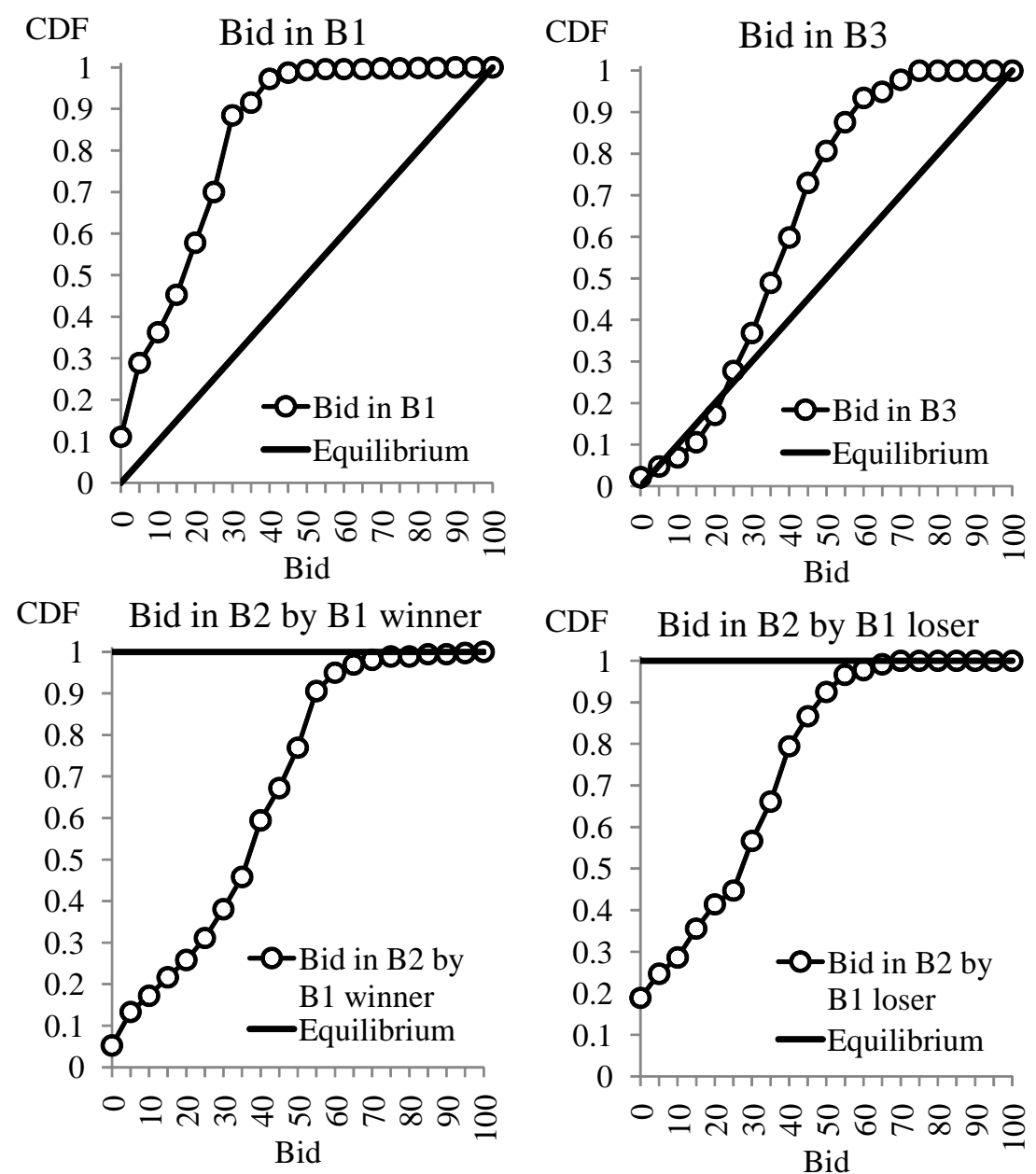


\section{Appendix (Not for Publication): Instructions for Sequential Treatment}

\section{GENERAL INSTRUCTIONS}

This is an experiment in the economics of strategic decision making. Various research agencies have provided funds for this research. The instructions are simple. If you follow them closely and make appropriate decisions, you can earn an appreciable amount of money.

The experiment will proceed in two parts. Each part contains decision problems that require you to make a series of economic choices which determine your total earnings. The currency used in Part 1 of the experiment is U.S. Dollars. The currency used in Part 2 of the experiment is francs. These francs will be converted to U.S. Dollars at a rate of $\mathbf{2 5}$ francs to $\mathbf{1}$ dollar. You have already received a $\mathbf{\$ 2 0 . 0 0}$ participation fee (this includes your showup fee of \$7.00). Your earnings from both Part 1 and Part 2 of the experiment will be incorporated into your participation fee. At the end of today's experiment, you will be paid in private and in cash. There are $\mathbf{1 2}$ participants in today's experiment.

It is very important that you remain silent and do not look at other people's work. If you have any questions, or need assistance of any kind, please raise your hand and an experimenter will come to you. If you talk, laugh, exclaim out loud, etc., you will be asked to leave and you will not be paid. We expect and appreciate your cooperation.

\section{INSTRUCTIONS FOR PART 1}

In this part of the experiment you will be asked to make a series of choices in decision problems. How much you receive will depend partly on chance and partly on the choices you make. The decision problems are not designed to test you. What we want to know is what choices you would make in them. The only right answer is what you really would choose.

For each line in the table in the next page, please state whether you prefer option A or option B. Notice that there are a total of $\mathbf{1 5}$ lines in the table but only one line will be randomly selected for payment. Each line is equally likely to be selected, and you do not know which line will be selected when you make your choices. Hence you should pay attention to the choice you make in every line. After you have completed all your choices a token will be randomly drawn out of a bingo cage containing tokens numbered from 1 to 15. The token number determines which line is going to be selected for payment.

Your earnings for the selected line depend on which option you chose: If you chose option A in that line, you will receive $\mathbf{\$ 1}$. If you chose option B in that line, you will receive either $\mathbf{\$ 3}$ or $\mathbf{\$ 0}$. To determine your earnings in the case you chose option B there will be second random draw. A token will be randomly drawn out of the bingo cage now containing twenty tokens numbered from 1 to 20. The token number is then compared with the numbers in the line selected (see the table). If the token number shows up in the left column you earn $\$ 3$. If the token number shows up in the right column you earn $\$ 0$.

While you have all the information in the table, we ask you that you input all your 15 decisions into the computer. The actual earnings for this part will be determined at the end of part 2, and will be independent of part 2 earnings.

\begin{tabular}{|l|l||l|l||l|}
\hline $\begin{array}{l}\text { Deci } \\
\text { sion } \\
\text { no. }\end{array}$ & $\begin{array}{c}\text { Opti } \\
\text { on } \mathbf{A}\end{array}$ & \multicolumn{2}{|c|}{$\begin{array}{c}\text { Option } \\
\mathbf{B}\end{array}$} & $\begin{array}{c}\text { Please } \\
\text { choose } \\
\text { A or B }\end{array}$ \\
\hline 1 & $\mathbf{\$ 1}$ & $\mathbf{\$ 3}$ never & $\mathbf{\$ 0}$ if $1,2,3,4,5,6,7,8,9,10,11,12,13,14,15,16,17,18,19,20$ & \\
\hline 2 & $\mathbf{\$ 1}$ & $\mathbf{\$ 3}$ if 1 comes out of the bingo cage & $\mathbf{\$ 0}$ if $2,3,4,5,6,7,8,9,10,11,12,13,14,15,16,17,18,19,20$ & \\
\hline 3 & $\mathbf{\$ 1}$ & $\mathbf{\$ 3}$ if 1 or 2 & $\mathbf{\$ 0}$ if $3,4,5,6,7,8,9,10,11,12,13,14,15,16,17,18,19,20$ & \\
\hline 4 & $\mathbf{\$ 1}$ & $\mathbf{\$ 3}$ if $1,2,3$ & $\mathbf{\$ 0}$ if $4,5,6,7,8,9,10,11,12,13,14,15,16,17,18,19,20$ & \\
\hline 5 & $\mathbf{\$ 1}$ & $\mathbf{\$ 3}$ if $1,2,3,4$, & $\mathbf{\$ 0}$ if $5,6,7,8,9,10,11,12,13,14,15,16,17,18,19,20$ & \\
\hline 6 & $\mathbf{\$ 1}$ & $\mathbf{\$ 3}$ if $1,2,3,4,5$ & $\mathbf{\$ 0}$ if $6,7,8,9,10,11,12,13,14,15,16,17,18,19,20$ & \\
\hline 7 & $\mathbf{\$ 1}$ & $\mathbf{\$ 3}$ if $1,2,3,4,5,6$ & $\mathbf{\$ 0}$ if $7,8,9,10,11,12,13,14,15,16,17,18,19,20$ & \\
\hline 8 & $\mathbf{\$ 1}$ & $\mathbf{\$ 3}$ if $1,2,3,4,5,6,7$ & $\mathbf{\$ 0}$ if $8,9,10,11,12,13,14,15,16,17,18,19,20$ & \\
\hline 9 & $\mathbf{\$ 1}$ & $\mathbf{\$ 3}$ if $1,2,3,4,5,6,7,8$ & $\mathbf{\$ 0}$ if $9,10,11,12,13,14,15,16,17,18,19,20$ & \\
\hline 10 & $\mathbf{\$ 1}$ & $\mathbf{\$ 3}$ if $1,2,3,4,5,6,7,8,9$ & $\mathbf{\$ 0}$ if $10,11,12,13,14,15,16,17,18,19,20$ & \\
\hline 11 & $\mathbf{\$ 1}$ & $\mathbf{\$ 3}$ if $1,2,3,4,5,6,7,8,9,10$ & $\mathbf{\$ 0}$ if $11,12,13,14,15,16,17,18,19,20$ & \\
\hline 12 & $\mathbf{\$ 1}$ & $\mathbf{\$ 3}$ if $1,2,3,4,5,6,7,8,9,10,11$ & $\mathbf{\$ 0}$ if $12,13,14,15,16,17,18,19,20$ & \\
\hline 13 & $\mathbf{\$ 1}$ & $\mathbf{\$ 3}$ if $1,2,3,4,5,6,7,8,9,10,11,12$ & $\mathbf{\$ 0}$ if $13,14,15,16,17,18,19,20$ & \\
\hline 14 & $\mathbf{\$ 1}$ & $\mathbf{\$ 3}$ if $1,2,3,4,5,6,7,8,9,10,11,12,13$ & $\mathbf{\$ 0}$ if $14,15,16,17,18,19,20$ & \\
\hline 15 & $\mathbf{\$ 1}$ & $\mathbf{\$ 3}$ if $1,2,3,4,5,6,7,8,9,10,11,12,13,14$ & $\mathbf{\$ 0}$ if $15,16,17,18,19,20$ & \\
\hline
\end{tabular}




\section{INSTRUCTIONS FOR PART 2}

\section{YOUR DECISION}

The second part of the experiment consists of $\mathbf{2 0}$ decision-making periods. The 12 participants in today's experiment will be randomly re-matched every period into 6 groups with 2 participants in each group. Therefore, the specific person who is the other participant in your group will change randomly after each period. The group assignment is anonymous, so you will not be told which of the participants in this room are assigned to your group

Each period consists of a maximum of three rounds. The period ends when one of the participants wins two of the three rounds ("best of three"). Thus, each period will consist of either two or three rounds. In each round, you and the other participant in your group will simultaneously make a bid (any number, including 0.1 decimal points). Your bid in each round cannot exceed 100 francs. The more you bid, the more likely you are to win a particular round. This will be explained in more detail later. The participant who is first to win two rounds receives the reward of $\mathbf{1 0 0}$ francs. Your total earnings depend on whether you receive the reward or not and how many francs you spent on bidding. An example of your decision screen is shown below in Figure 1:

Figure 1 - Decision Screen

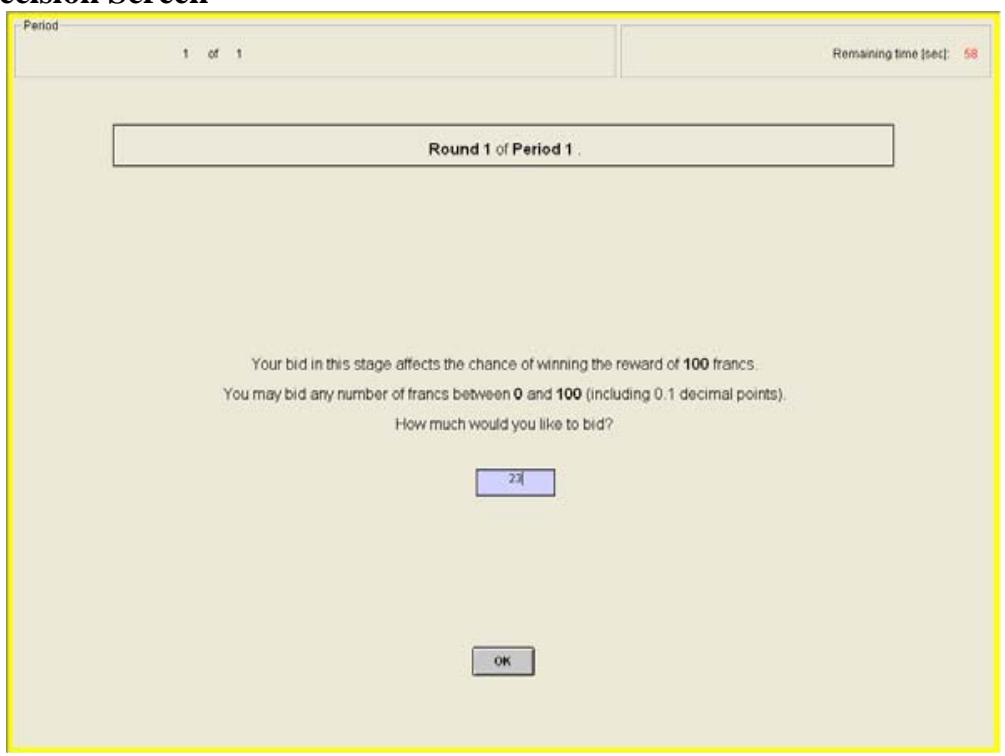

\section{CHANCE OF WINNING A ROUND}

If you bid more than the other participant in a particular round you win that round with certainty. So, if you bid 30 francs in a particular round while the other participant bids 29.9 francs in the same round then the computer will chose you as the winner of that round. In case both participants bid the same amount in the same round, the computer determines randomly who wins that round. In case both participants bid zero, the computer determines randomly who wins the round.

\section{YOUR EARNINGS}

Your earnings depend on whether you receive the reward or not and how many francs you spent on bidding. The participant who is first to win two rounds receives the reward of $\mathbf{1 0 0}$ francs. Regardless of who receives the reward, both participants will have to pay their bids in each round. Thus, the period earnings will be calculated in the following way:

(1) If the period lasted for only two rounds

Earnings of the participant who won both rounds are $=$ $=100-($ bid in round 1$)-($ bid in round 2$)$

Earnings of the participant who won neither rounds are = $=0-($ bid in round 1$)-($ bid in round 2$)$

(2) If the period lasted for three rounds

Earnings of the participant who won two rounds are $=$ $=100-($ bid in round 1$)-($ bid in round 2$)-($ bid in round 3$)$

Earnings of the participant who won one round are $=$ $=0-($ bid in round 1$)-($ bid in round 2$)-($ bid in round 3$)$ 


\section{END OF THE ROUND}

After both participants make their round bids, the computer will determine the winner of the round. Both participants will observe the outcome of the round - your bid, other participant's bid and winner, as shown in Figure 2. Then they make bids in another round. This continues until one of the participants in the group wins two rounds.

Figure 2 - Intermediate Screen

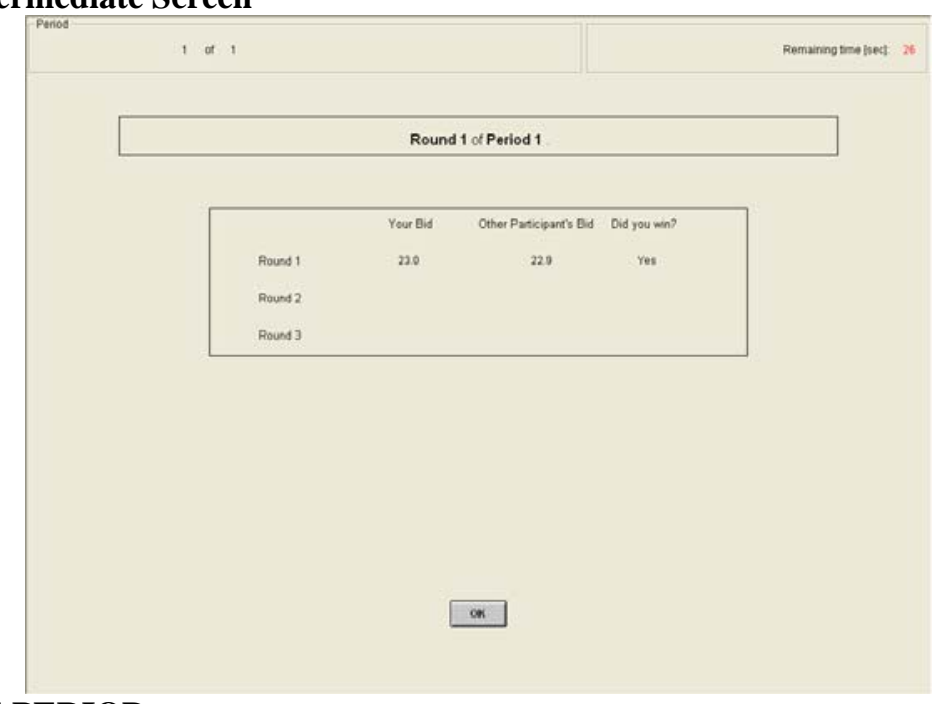

\section{END OF THE PERIOD}

The period ends when one of the participants in the group wins two rounds. At the end of the period, the computer will calculate your period earnings based on whether you received the reward or not and how many francs you spent on bidding in each round. Your earnings from that period will be reported on the outcome screen as shown in Figure 3. Once the outcome screen is displayed you should record your results for the period on your Personal Record Sheet under the appropriate heading. You will be randomly re-matched with a different participant at the start of the next period.

Figure 3 - Outcome Screen

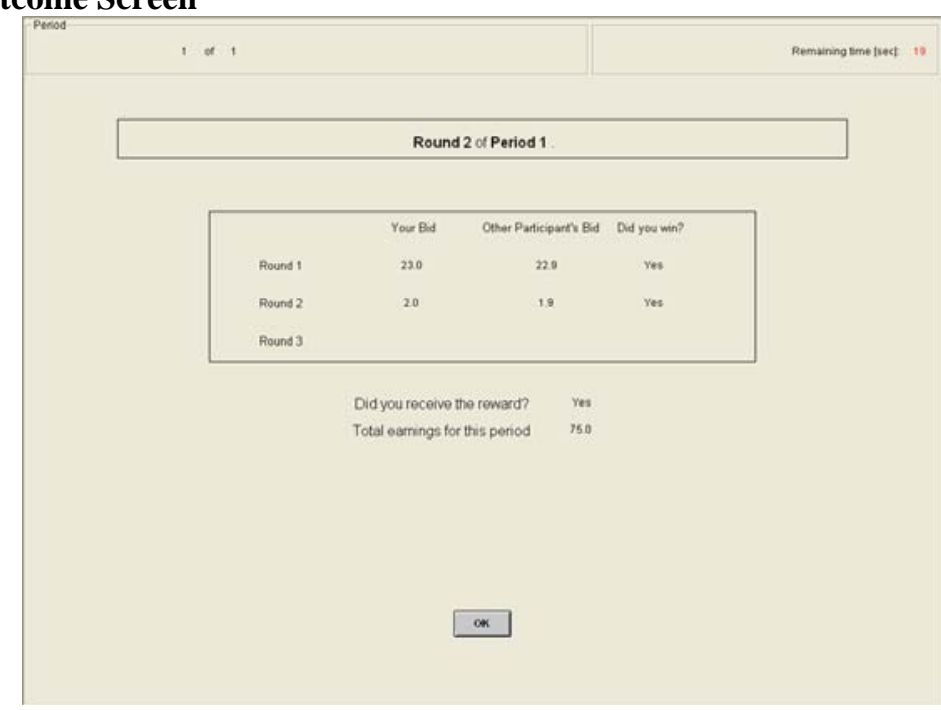

\section{END OF THE EXPERIMENT}

At the end of the experiment we will use the bingo cage to randomly select 2 out of 20 periods for actual payment. Depending on the outcome in a given period, you may receive either positive or negative earnings. You will sum the total earnings for these 2 periods and convert them to a U.S. dollar payment, as shown on the last page of your personal record sheet. Remember you have already received a $\mathbf{\$ 2 0 . 0 0}$ participation fee (equivalent to $\mathbf{5 0 0}$ francs). If your earnings from this part of the experiment are positive, we will add them to your participation fee. If your earnings are negative, we will subtract them from your participation fee.

\section{Are there any questions?}


2012

\section{Economic Science Institute Working Papers}

12-05 Sheremeta, R. and Shields, T. Do Liars Believe? Beliefs and Other-Regarding Preferences in Sender-Receiver Games.

12-04 Sheremeta, R., Masters, W. and Cason. T. Winner-Take-All and Proportional-Prize Contests:

Theory and Experimental Results.

12-03 Buchanan, J., Gjerstad, S. and Smith, V. There’s No Place Like Home.

12-02 Corgnet, B. and Rodriguez-Lara, I. Are you a Good Employee or Simply a Good Guy? Influence Costs and Contract Design.

12-01 Kimbrough, E. and Sheremeta, R. Side-Payments and the Costs of Conflict.

2011

11-19 Cason, T., Savikhin, A. and Sheremeta, R. Behavioral Spillovers in Coordination Games.

11-18 Munro, D. and Rassenti, S. Combinatorial Clock Auctions: Price Direction and Performance.

11-17 Schniter, E., Sheremeta, R., and Sznycer, D. Restoring Damaged Trust with Promises, Atonement and Apology.

11-16 Brañas-Garza, P., and Proestakis, A. Self-discrimination: A field experiment on obesity.

11-15 Brañas-Garza, P., Bucheli, M., Paz Espinosa, M., García-Muñoz, T. Moral cleansing and moral licenses: experimental evidence.

11-14 Caginalp, G., Porter, D., and Hao, L. Asset Market Reactions to News: An Experimental Study.

11-13 Porter, D., Rassenti, S. and Smith, V. The Effect of Bidding Information in Ascending Auctions.

11-12 Schniter, E., Sheremeta, R. and Shields, T. Conflicted Minds: Recalibrational Emotions Following Trust-based Interaction.

11-11 Pedro Rey-Biel, P., Sheremeta, R. and Uler, N. (Bad) Luck or (Lack of) Effort?: Comparing Social Sharing Norms between US and Europe.

11-10 Deck, C., Porter, D., Smith, V. Double Bubbles in Assets Markets with Multiple Generations. 
11-09 Kimbrough, E., Sheremeta, R., and Shields, T. Resolving Conflicts by a Random Device.

11-08 Brañas-Garza, P., García-Muñoz, T., and Hernan, R. Cognitive effort in the Beauty Contest Game. 11-07 Grether, D., Porter, D., and Shum, M. Intimidation or Impatience? Jump Bidding in On-line Ascending Automobile Auctions.

11-06 Rietz, T., Schniter, E., Sheremeta, R., and Shields, T. Trust, Reciprocity and Rules.

11-05 Corgnet, B., Hernan-Gonzalez, R., and Rassenti, S. Real Effort, Real Leisure and Real-time Supervision: Incentives and Peer Pressure in Virtual Organizations.

11-04 Corgnet, B. and Hernán-González R. Don’t Ask Me If You Will Not Listen: The Dilemma of Participative Decision Making.

11-03 Rietz, T., Sheremeta, R., Shields, T., Smith, V. Transparency, Efficiency and the Distribution of Economic Welfare in Pass-Through Investment Trust Games.

11-02 Corgnet, B., Kujal, P. and Porter, D. The Effect of Reliability, Content and Timing of Public Announcements on Asset Trading Behavior.

11-01 Corgnet, B., Kujal, P. and Porter, D. Reaction to Public Information in Markets: How Much Does Ambiguity Matter?

2010

10-23 Sheremeta, R. Perfect-Substitutes, Best-Shot, and Weakest-Link Contests between Groups. 10-22 Mago, S., Sheremeta, R., and Yates, A. Best-of-Three Contests: Experimental Evidence. 10-21 Kimbrough, E. and Sheremeta, R. Make Him an Offer He Can't Refuse: Avoiding Conflicts Through Side Payments.

10-20 Savikhim, A. and Sheremeta, R. Visibility of Contributions and Cost of Inflation: An Experiment on Public Goods.

10-19 Sheremeta, R. and Shields, T. Do Investors Trust or Simply Gamble?

10-18 Deck, C. and Sheremeta, R. Fight or Flight? Defending Against Sequential Attacks in the Game of Siege. 
10-17 Deck, C., Lin, S. and Porter, D. Affecting Policy by Manipulating Prediction Markets:

Experimental Evidence.

10-16 Deck, C. and Kimbrough, E. Can Markets Save Lives? An Experimental Investigation of a Market for Organ Donations.

10-15 Deck, C., Lee, J. and Reyes, J. Personality and the Consistency of Risk Taking Behavior:

Experimental Evidence.

10-14 Deck, C. and Nikiforakis, N. Perfect and Imperfect Real-Time Monitoring in a Minimum-Effort Game.

10-13 Deck, C. and Gu, J. Price Increasing Competition? Experimental Evidence.

10-12 Kovenock, D., Roberson, B.,and Sheremeta, R. The Attack and Defense of Weakest-Link Networks.

10-11 Wilson, B., Jaworski, T., Schurter, K. and Smyth, A. An Experimental Economic History of Whalers’ Rules of Capture.

10-10 DeScioli, P. and Wilson, B. Mine and Thine: The Territorial Foundations of Human Property. 10-09 Cason, T., Masters, W. and Sheremeta, R. Entry into Winner-Take-All and Proportional-Prize Contests: An Experimental Study.

10-08 Savikhin, A. and Sheremeta, R. Simultaneous Decision-Making in Competitive and Cooperative Environments.

10-07 Chowdhury, S. and Sheremeta, R. A generalized Tullock contest.

10-06 Chowdhury, S. and Sheremeta, R. The Equivalence of Contests.

10-05 Shields, T. Do Analysts Tell the Truth? Do Shareholders Listen? An Experimental Study of Analysts' Forecasts and Shareholder Reaction.

10-04 Lin, S. and Rassenti, S. Are Under- and Over-reaction the Same Matter? A Price Inertia based Account.

10-03 Lin, S. Gradual Information Diffusion and Asset Price Momentum.

10-02 Gjerstad, S. and Smith, V. Household expenditure cycles and economic cycles, 1920 - 2010. 
10-01 Dickhaut, J., Lin, S., Porter, D. and Smith, V. Durability, Re-trading and Market Performance. 2009

09-11 Hazlett, T., Porter, D., Smith, V. Radio Spectrum and the Disruptive Clarity OF Ronald Coase.

09-10 Sheremeta, R. Expenditures and Information Disclosure in Two-Stage Political Contests.

09-09 Sheremeta, R. and Zhang, J. Can Groups Solve the Problem of Over-Bidding in Contests?

09-08 Sheremeta, R. and Zhang, J. Multi-Level Trust Game with "Insider" Communication.

09-07 Price, C. and Sheremeta, R. Endowment Effects in Contests.

09-06 Cason, T., Savikhin, A. and Sheremeta, R. Cooperation Spillovers in Coordination Games.

09-05 Sheremeta, R. Contest Design: An Experimental Investigation.

09-04 Sheremeta, R. Experimental Comparison of Multi-Stage and One-Stage Contests.

09-03 Smith, A., Skarbek, D., and Wilson, B. Anarchy, Groups, and Conflict: An Experiment on the Emergence of Protective Associations.

09-02 Jaworski, T. and Wilson, B. Go West Young Man: Self-selection and Endogenous Property Rights.

09-01 Gjerstad, S. Housing Market Price Tier Movements in an Expansion and Collapse. 2008

08-09 Dickhaut, J., Houser, D., Aimone, J., Tila, D. and Johnson, C. High Stakes Behavior with Low Payoffs: Inducing Preferences with Holt-Laury Gambles.

08-08 Stecher, J., Shields, T. and Dickhaut, J. Generating Ambiguity in the Laboratory.

08-07 Stecher, J., Lunawat, R., Pronin, K. and Dickhaut, J. Decision Making and Trade without Probabilities.

08-06 Dickhaut, J., Lungu, O., Smith, V., Xin, B. and Rustichini, A. A Neuronal Mechanism of Choice. 08-05 Anctil, R., Dickhaut, J., Johnson, K., and Kanodia, C. Does Information Transparency Decrease Coordination Failure?

08-04 Tila, D. and Porter, D. Group Prediction in Information Markets With and Without Trading Information and Price Manipulation Incentives. 
08-03 Thomas, C. and Wilson, B. Horizontal Product Differentiation in Auctions and Multilateral Negotiations.

08-02 Oprea, R., Wilson, B. and Zillante, A. War of Attrition: Evidence from a Laboratory Experiment on Market Exit.

08-01 Oprea, R., Porter, D., Hibbert, C., Hanson, R. and Tila, D. Can Manipulators Mislead Prediction Market Observers? 